\title{
Transformation of a glandular odontogenic cyst into mucoepidermoid carcinoma of the mandible: A case report
}

\section{Transformacja zębopochodnej torbieli gruczołowej w raka śluzowo-płaskonabłonkowego żuchwy - opis przypadku}

\author{
Mateusz Dymek ${ }^{1,2, A-F}$, Mariusz Książek ${ }^{3, C-E}$, Bogumił Lewandowski, ${ }^{2, A, E, F}$ \\ ${ }^{1}$ Collegium Medicum of the University of Rzeszów, Poland \\ ${ }^{2}$ Department of Maxillofacial Surgery, Fryderyk Chopin Clinical Voivodeship Hospital No.1 in Rzeszów, Poland \\ ${ }^{3}$ Department of Pathology, MedLifeCover, Krosno, Poland \\ A - research concept and design; $\mathrm{B}$ - collection and/or assembly of data; $\mathrm{C}$ - data analysis and interpretation; \\ $D$ - writing the article; $E$ - critical revision of the article; $F$ - final approval of the article
}

Address for correspondence

Mateusz Dymek

E-mail: faceinstytut@gmail.com

Funding sources

None declared

Conflict of interest

None declared

Received on February 6, 2019

Reviewed on May 1, 2019

Accepted on June 3, 2019

Published online on September 30, 2019

Dymek M, Książek M, Lewandowski B. Transformation of a glandular odontogenic cyst into mucoepidermoid carcinoma of the mandible: A case report. Dent Med Probl. 2019;56(3):311-316. doi:10.17219/dmp/109807

D0I

$10.17219 / \mathrm{dmp} / 109807$

Copyright

(c) 2019 by Wroclaw Medical University

This is an article distributed under the terms of the

Creative Commons Attribution 3.0 Unported License (CC BY 3.0)

(https://creativecommons.org/licenses/by/3.0/)

\section{Abstract}

The glandular odontogenic cyst $(\mathrm{GOC})$ is a rare pathology of odontogenic origin, which can behave unpredictably. It is problematic in clinical, radiographic and histological diagnostics. Intraosseous mucoepidermoid carcinoma (MEC) is a rare tumor which affects the jaws, typically found in the mandible. This malignancy, which usually originates from the salivary glands, can also be caused by a transformation of the mucous cells found in odontogenic cysts.

This article presents a rare case of $\mathrm{GOC}$ transforming into MEC of the mandible, which was reported during the treatment of a 52-year-old male patient. The aim of this work was to present some of the therapeutic and clinical difficulties encountered when $\mathrm{GOC}$ transforms into mucoepidermoid cancer in the mandible, considering the pathomorphological and histological differentiations. The differentiation between MEC and $\mathrm{GOC}$ might be difficult through microscopic examination and requires the cooperation of a clinician - a maxillofacial surgeon - and a histopathologist.

Key words: glandular odontogenic cyst, mucoepidermoid carcinoma, neoplastic transformation

Słowa kluczowe: zębopochodna torbiel gruczołowa, rak śluzowo-płaskonabłonkowy, transformacja nowotworowa 


\section{Introduction}

According to the current literature, glandular odontogenic cysts (GOCs) are rare and they constitute $0.012-1.3 \%$ of all cysts located in the facial part of the skull. ${ }^{1}$ The condition was first described in 1987 by Padayachee and Van Wyk in 2 cases known as 'sialo-odontogenic cysts.' In 1988, Gardner et al. introduced the term 'glandular odontogenic cyst, ${ }^{3}$ and the World Health Organization (WHO) included this term in their classification of odontogenic tumors published in 1992. Approximately 180 GOC cases have been documented in the medical literature to date. ${ }^{2-4}$ The glandular odontogenic cyst is marginally more common in men (1.3:1), with peak morbidity occurring in the patient's 60s. In most cases described, these cysts were located in the mandible, primarily in its anterior section. ${ }^{5}$ At its early stages, the cyst develops slowly and asymptomatically in the form of a tumor located in the bone; it is frequently detected accidentally. Even when a tumor is detected randomly in the X-ray of the bone, with minimal facial asymmetry but without the presence of pain, it does not raise any concern in the patient. ${ }^{6}$

The etiology of the glandular cyst is still not clear. In the literature, the link between GOCs and the salivary gland tissue has been primarily stressed. At present, most authors point to the association with the odontogenic epithelium, and the etiological resemblance to lesions such as periodontal cysts, follicular cysts and odontogenic acinic cysts. Clinically, GOC is manifested in the tenderness of the bone, which is deformed, and the dilation of the cortical bone layer, frequently with discontinuation (perforation), accompanied by parchment crunch or fluctuation. Advanced lesions are accompanied by sensory disorders, pain and paresthesia. ${ }^{7,8}$

Microscopy often presents diagnostic difficulties. The morphological structure of the GOC epithelium contains the odontogenic cells and the elements of the secretory gland cells. Fowler et al. stated that the microscopic diagnosis of GOC should be based on the presence of at least 7 out of 10 microscopic parameters: surface eosinophilic cuboidal cells, intraepithelial microcysts, apocrine snouts, vacuolated cells, variable thickness of the cyst lining, papillary projections, mucous goblet cells, epithelial spheres, cilia, and multiple cystic spaces. ${ }^{4}$ The pathomorphological diagnosis may be impaired and requires differentiation with intraosseous mucoepidermoid carcinoma (MEC). There are some features that are present in GOC but not in MEC, which permit a histopathologist to differentiate the 2 conditions. These include a lack of the aforementioned structures and a swirling pattern within the carcinoma. Another important feature to differentiate between GOC and MEC is the presence of more complex solid or follicular structures within the proliferating epithelium in MEC and its unequivocal invasion. ${ }^{9,10}$ Additional immunohistochemistry (the expression of cytokeratin 18 (CK-18), cytokeratin 19 (CK-19), p53, and
Ki-67) may be helpful in the differential diagnosis. ${ }^{11-13}$ The $M A M L 2$ gene rearrangements have been found to be specific to MEC. ${ }^{14}$

The radiological image is unremarkable, exhibiting no pathognomonic features distinguishing GOC from other pathological lesions in the facial part of the skull which take the form of multi-cavity bone structure defects, and cause bulging and dilatation, mainly of the cortical layer of the involved bone. Cavities in the cortical bone layer are often described as perforations. In radiological diagnostic imaging, GOC should be differentiated from radicular cyst, ameloblastoma, odontogenic keratocyst, solitary bone cyst, and central giant cell lesions. ${ }^{15}$

The choice of treatment depends on the size, shape and structure of the lesion. Large lesions, with a multi-chamber structure, may have a more aggressive course and require complete eradication with a wide excision margin of healthy tissue, frequently with peripheral osteoectomy. The prevalence of GOC recurrence is estimated to be approx. 10-30\%. ${ }^{9}$ The onset of recurrence takes place approx. 2.7 years after resection on average. Due to the risk of GOC transforming into highly differentiated $M E C$, patients require regular clinical and radiological follow-ups, for up to 3 years or even longer. ${ }^{16}$

Numerous authors have identified the similarity and association of GOC with MEC. ${ }^{17}$ Microscopically, both of these lesions exhibit some common features. Gardner et al. presented a case of MEC which developed from the GOC lining cells. ${ }^{3}$ The microscopic morphology of GOC and MEC may be similar, and they may frequently appear ambiguous in their differentiation. ${ }^{18,19}$

An example of therapeutic difficulties is the case of GOC transforming into MEC in the mandible of a 52-year-old man who was recently treated at the Department of Maxillofacial Surgery at Fryderyk Chopin Clinical Voivodeship Hospital No. 1 in Rzeszów, Poland.

\section{Case report}

A 52-year-old male patient was referred by a dentist to the Department of the Maxillofacial Surgery at the Clinical Voivodeship Hospital No.1 in Rzeszów, Poland, due to a bulge in the alveolar region of his left mandible, which he had noticed 3 months earlier; there were no other clinical signs and the patient was otherwise in good general health. Examination revealed some asymmetry in the left cheek, due to the presence of a lump in the mandibular angle. The regional lymph nodes were impalpable. Intraoral examination revealed a hard painless lump, covered with thickened, otherwise normal mucosa. This lesion caused the shortening of the oral vestibule due to the toothless alveolar part of the mandible, in the section from tooth 35 to the area of the retromolar trigon, toward the mandibular ramus. Tooth 35 , directly adjacent to the lesion, did not exhibit pathological mobility. The multiple 
osteolytic defects of the alveolus of the left side of the mandible, from tooth 35 to the mandibular ramus, were found in pantomographic imaging (Fig. 1).

Computed tomography $(\mathrm{CT})$ revealed multiple, extensive osteolytic defects associated with the bone lesions in the area of the mandibular corpus and the alveolar part of the left mandible, measuring $36 \mathrm{~mm} \times 27 \mathrm{~mm} \times$ $27 \mathrm{~mm}$, which caused the thinning of the cortex layer. These lesions approached the mandibular ramus. On the side of the proper oral cavity, at the level of the mandibular ramus, a focus of soft tissue measuring approx. $2 \mathrm{~cm} \times 1.3 \mathrm{~cm} \times 1.5 \mathrm{~cm}$ was found; it showed a strong contrast enhancement from $62 \mathrm{HU}$ to $92 \mathrm{HU}$. Lymph node levels Ib, II and III of the neck on the left side were enlarged to as much as $13 \mathrm{~mm}$ (Fig. 2). The microscopic examination of the tumor specimen revealed the presence of GOC (Fig. 3). The patient was qualified for the surgical removal of the cyst located in the mandibular corpus and ramus as well as for the extraction of tooth 35 , which was in the lumen of the cyst. The surgical procedure was performed. Intraoperatively, the lesion was found to have a typical capsule filled with fluid on the medial side, in the area of teeth 34-36. In the distal aspect, located in the mandible angle, the bone cavity was filled with something that macroscopically resembled the granulation tissue.

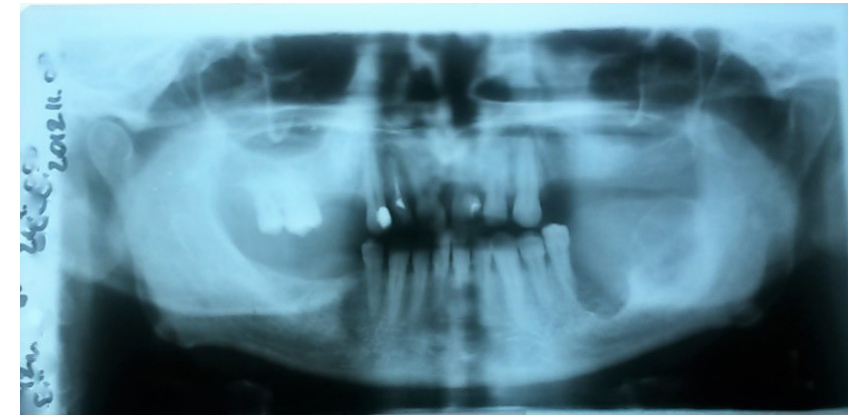

Fig. 1. Orthopantomography showing the tumor on the left side

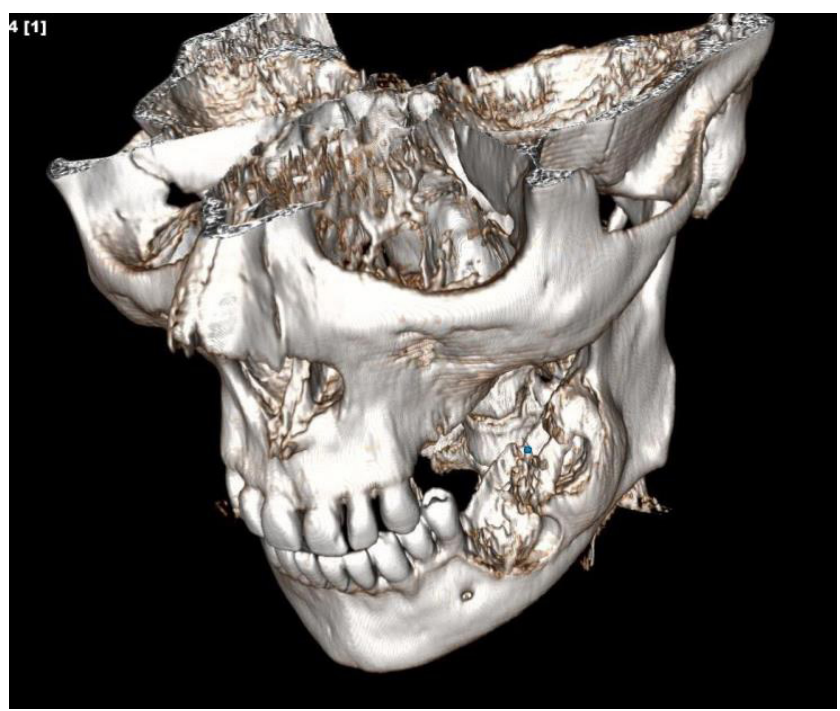

Fig. 2. Computed tomography (CT) scan of the left side of the mandible showing the tumor

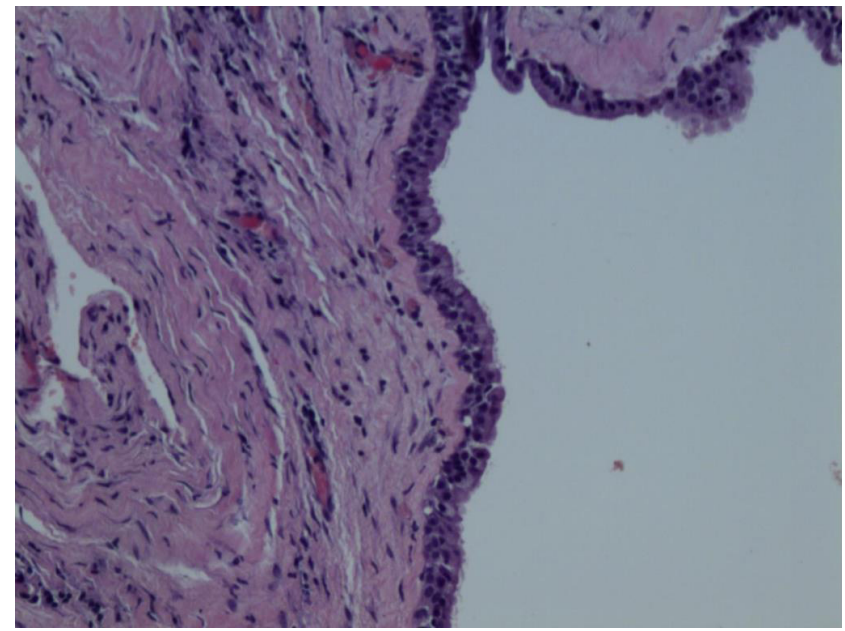

Fig. 3. Microscopic image of the characteristic epithelium of the glandular odontogenic cyst (GOC), composed of a slightly atrophic squamous layer with overlying ciliated, columnar epithelium

Hematoxylin and eosin staining $(H \& E) ; \times 4$ magnification.

The postoperative course was uneventful. The histopathological examination of the surgical specimen confirmed the presence of GOC. The patient was discharged on the $5^{\text {th }}$ day after surgery with a recommendation for periodic monitoring and follow-ups at the hospital outpatient clinic. The microscopic image of the surgical specimen is shown in Fig. 4.

In the $1^{\text {st }}$ year after surgery, the patient regularly returned for follow-ups. During the follow-ups, uneventful healing was observed. After a year, he arbitrarily discontinued monitoring and did not appear at the clinic for his appointments. He reappeared 2 years later because of swelling in his cheek, difficulties in opening and closing his jaw, and pain in his left mandibular angle. These ailments had appeared a few days earlier. External and internal oral examination suggested the recurrence of the cyst in the area of teeth $35-36$, in the form of a lump

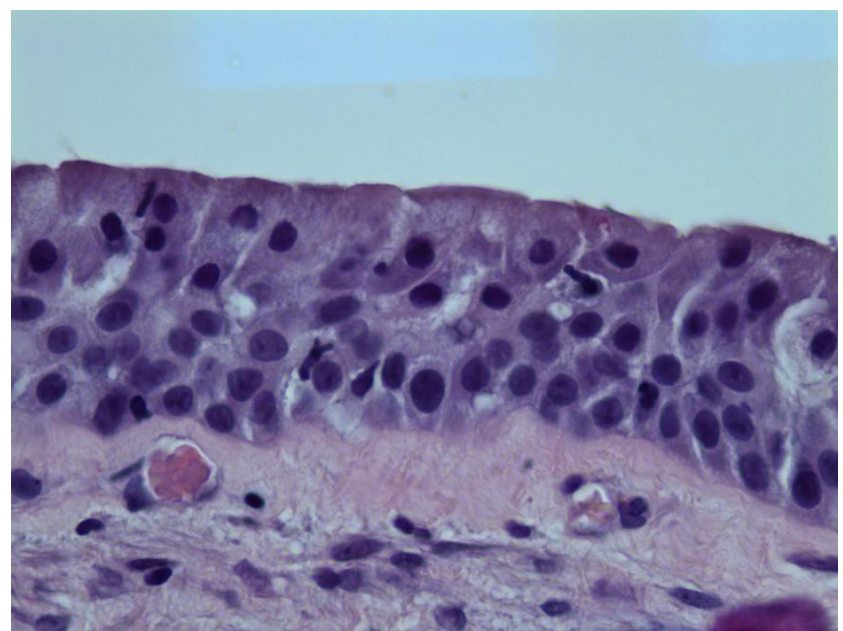

Fig. 4. Microscopic image exhibiting the details of the glandular odontogenic cyst (GOC) epithelium, in this case with only a few cilia present

$\mathrm{H} \& \mathrm{E} ; \times 40$ magnification. 
$3 \mathrm{~cm}$ in diameter, which was non-movable, elastic-hard and covered with normal-appearing mucosa. It caused the shortening of the oral vestibule and manifested itself in facial asymmetry on the left side. Computed tomography in combination with examination performed prior to the operation exhibited a progression in the form of exacerbated degenerative-osteolytic lesions in the mandible, including the mandibular corpus and ramus, i.e., the area of teeth 35-37 (Fig. 5), with damage to the mandibular lower margin. The defect was filled with low-density soft tissue. The lymph nodes were not enlarged. Computed tomography pointed to the recurrence of the cyst (Fig. 5). The histopathological examination of the recurrent cyst biopsy specimen revealed a relapse of GOC (Fig. 6).

Based on the histopathological and CT examination, the cyst was re-enucleated with more radical surgery, with the surrounding bone curetted to widen the surgical margins.

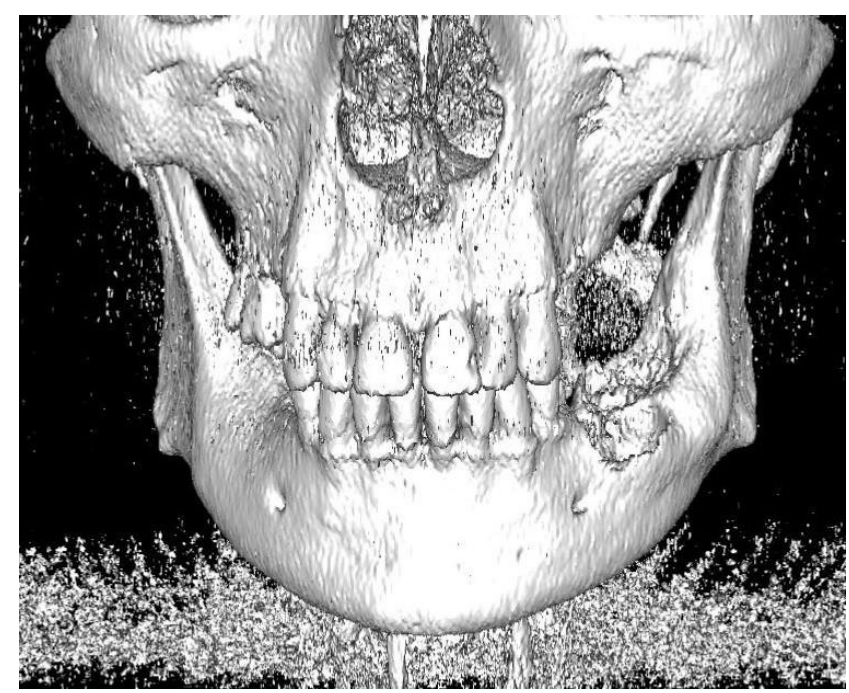

Fig. 5. Three-dimensional (3D) computed tomography (CT) scan presenting the recurring tumor on the left side

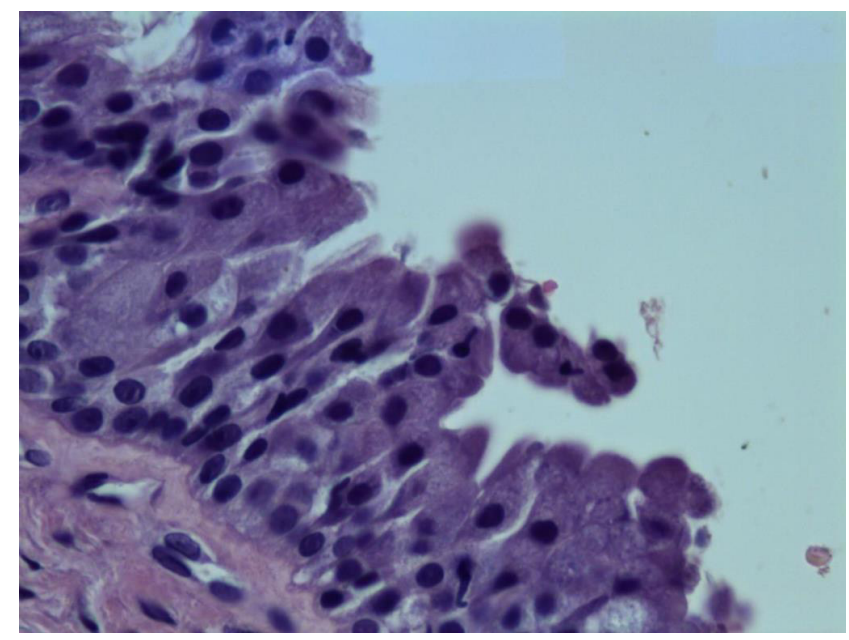

Fig. 6. Histopathologic diagnosis of the glandular odontogenic cyst (GOC) recurrence. Microscopic image showing overlying ciliated epithelium with pseudopapillae formation, with more basally located squamous differentiating cells

$H \& E_{;} \times 40$ magnification.
During the operation, damage to the bone lamella in the lower margin of the mandibular corpus was found. The tumor mass was primarily composed of what macroscopically appeared to be the granulation tissue. The histopathological examination of the surgical specimen revealed intermediate-grade MEC (MEC G2), adjacent to GOC. Coexisting GOC-specific areas were also present, which, coupled with the previous histopathological findings of the lesion, implicated a diagnosis of MEC arising from the previous GOC (Fig. 7). Due to the location and malignant nature of the tumor as well as the history of previous surgeries, a partial mandibular resection was planned in order to remove the MEC foci from the bone, combined with a selective left suprascapular-hyoid lymphangiectomy. The patient was offered a simultaneous reconstruction with microvascular bone transplant from the iliac bone and postoperative radiotherapy, but the patient did not consent to the proposed microvascular bone graft, instead accepting the alternative of reinforcing the mandible with a standard titanium implant for stabilizing bone stumps. The resection of the left mandibular corpus was extended to include a preventive excision of the left lymphatic system on the neck, up to the level of the omohyoid muscle. The post-resection bone defect of the mandible was managed with a standard titanium plate.

The histopathological examination of the final surgical specimen after mandibular tumor resection confirmed the presence of MEC arising from the pre-existing GOC (Fig. 8 A-D). The postoperative course was uneventful. The patient was discharged on the $5^{\text {th }}$ day after surgery and referred to the Radiotherapy Clinic to continue treatment with postoperative radiotherapy, where he received 60 Gy in 35 fractions. The course of the therapy was uneventful. Since radiotherapy, the patient has maintained regular surgical and oncological follow-ups.

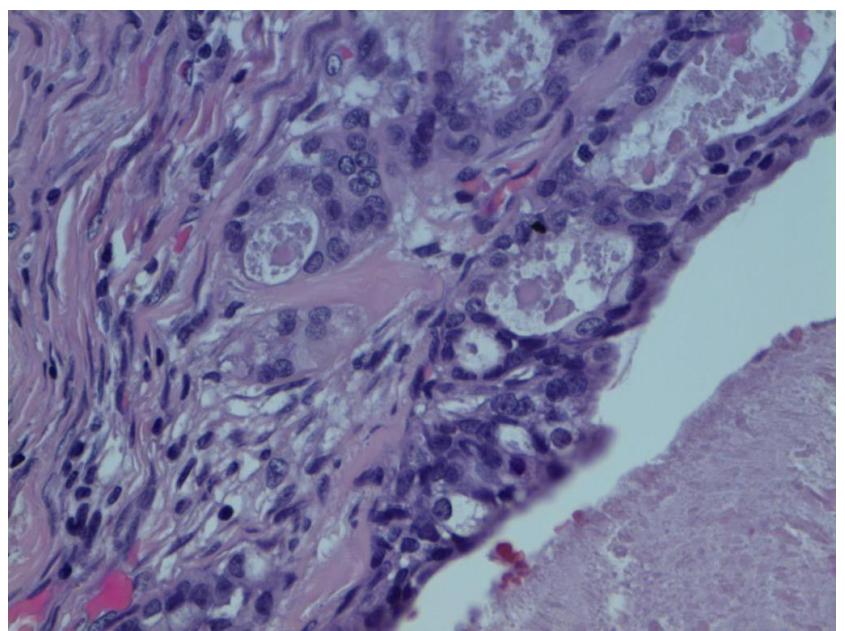

Fig. 7. Microscopic image of the surgical specimen after the removal of the recurring cyst. The malignant component on the left side of the picture are malignant glandular structures infiltrating the stroma; on the right side of the picture there is the remaining part of the glandular odontogenic cyst (GOC) with overlying epithelium

$\mathrm{H} \& \mathrm{E}_{;} \times 20$ magnification. 

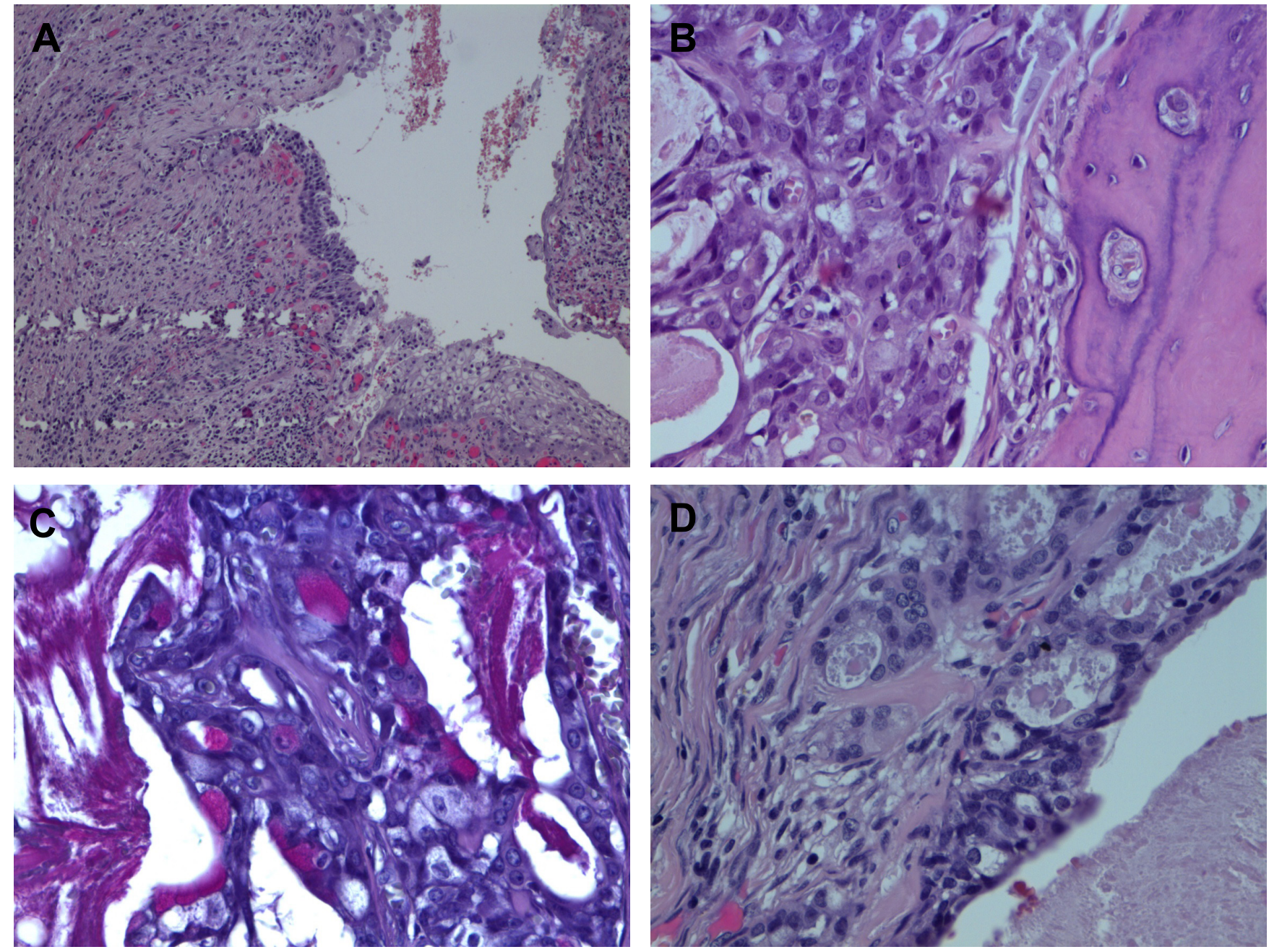

Fig. 8. Post-surgical specimen showing 2 components: one benign (glandular odontogenic cyst - GOC) and the other malignant (mucoepidermoid carcinoma - MEC) A - fragment of the benign component with the $\mathrm{GOC}$ overlying epithelium ( $\mathrm{H} \& \mathrm{E} ; \times 4$ magnification); $\mathrm{B}$ - bony structure infiltrated by MEC ( $\mathrm{H} \& \mathrm{E} ; \times 20$ magnification); C - MEC, positive for intraepithelial mucin (pink-colored) (mucicarmine staining; $\times 20$ magnification); D - solid and glandular areas of invasive MEC ( $\mathrm{H} \& \mathrm{E} ; \times 20$ magnification).

\section{Discussion}

The literature shows examples of the neoplastic transformation of epithelial jaw cysts, most of which are associated with keratocysts or inflammatory radicular cysts. ${ }^{20-22}$ According to Stoelinga and Bronkhorst, the prevalence of malignant neoplasms developing from epithelial cysts is approx. 2 out of 1,000 cases. ${ }^{23}$ The pathogenesis of this phenomenon has thus far remained unclear. The authors emphasize that the process of the malignant transformation of GOC into MEC can be attributed to factors occurring inside the cyst, including chronic and prolonged inflammation accompanying the cyst, various biochemical processes in the fluid of the cyst, and the mechanical irritation of the cyst by the fluid, resulting in the remodeling and keratinization of the cystic epithelium. ${ }^{24}$ In the case described herein, the cyst transformation may have been affected by a prolonged chronic condition prior to treatment and recurrence after cyst removal. Fowler et al. observed recurrence in half of the 46 patients treated. ${ }^{4}$ Mascitti et al. reported recurrence after ineffective cyst removal in $19.8 \%$ of the patients. ${ }^{25}$
Pires et al. suggested that many cases which were diagnosed as intraosseous MEC could be classified as lowgrade MEC. ${ }^{11}$ The glandular odontogenic cyst and lowgrade MEC have many features in common in terms of the similarity of clinical, radiological and microscopic images. Some authors highlight the possibility of the neoplastic transformation of the glandular epithelium of GOCs as one of the causes of MEC. According to the literature, GOCs have a higher likelihood of transforming into cancer. ${ }^{15,17,18}$ The clinical picture of MEC in the 52-year-old patient presented in this paper is consistent with the literature. ${ }^{5,9,18,24,26}$ Mucoepidermoid carcinoma, like GOC, belongs to a family of rare jawbone tumors. Cancer can develop from the ectopic foci of the glandular tissue associated with the bone itself, or, as in this case of the 52-year-old man, from the GOC epithelium. The tumor equally affects men and women. It is usually located in the lateral aspect of the mandible. The clinical and radiological pictures of both GOCs and MEC lesions, as mentioned above, do not differ significantly. A diagnosis of MEC dictates a therapeutic management 
involving a broad excision of the lesion with bone resection and lymphangiectomy. Approximately $10 \%$ of MEC tumors cause regional metastases to the cervical lymph nodes. The presented case is an example of the difficulties encountered by medical practitioners in the diagnosis and differentiation of GOC and MEC. As previously mentioned, there was a need for a maxillofacial surgeon and a histopathologist to provide clinical data, radiological images and other important test results that are necessary for a proper, unequivocal histopathological diagnosis. Therapeutic decisions should be made on the basis of a thorough individual assessment of the clinical picture, enhanced by radiographic images, taking into account the results of microscopic examination. The appearance of recurrent cysts at short intervals after surgery should arouse suspicion of transformation into low-grade MEC. Manojlović et al. observed the recurrence most frequently 2-3 years after surgery. ${ }^{17}$ Numerous authors believe that in the differential diagnosis between GOC and MEC, immunohistochemistry, cytokine expression, markers, and - more and more frequently - genetic tests are needed. ${ }^{10-14}$

\section{Conclusions}

Mucoepidermoid carcinoma can develop from the epithelial lining of GOC, which is confirmed by the available literature and our case of the 52-year-old patient. Despite the fact that both MEC and GOC are rare, they should be taken into account in the case of multiple large, cyst-like osteolytic defects located in the facial skeleton, primarily in the mandible, in the clinical radiological diagnosis, pathomorphology and differentiation between cysts and malignant bone tumors. The differentiation between MEC and GOC might be difficult on microscopic examination, requiring the cooperation of a maxillofacial surgeon and a histopathologist.

\section{ORCID iDs}

Mateusz Dymek (1) https://orcid.org/0000-0002-2001-8262 Mariusz Książek (1) https://orcid.org/0000-0002-9316-8034 Bogumił Lewandowski (1) https://orcid.org/0000-0002-8045-5093

\section{References}

1. Abdolsamadi $\mathrm{H}$, Sadr P, Barakian Y. Glandular odontogenic cyst: A case report. Avicenna J Dent Res. 2016;8(1):e25605.

2. Padayachee A, Van Wyk CW. Two cystic lesions with features of both the botryoid odontogenic cyst and the central mucoepidermoid tumour: Sialo-odontogenic cyst? J Oral Pathol. 1987;16(10):499-504.

3. Gardner DS, Kessler HP, Morency R, Schaffner DL. The glandular odontogenic cyst: An apparent entity. J Oral Pathol. 1988;17(8):359-366.

4. Fowler CB, Brannon RB, Kessler HP, Castle JT, Kahn MA. Glandular odontogenic cyst: Analysis of 46 cases with special emphasis on microscopic criteria for diagnosis. Head Neck Pathol. 2011;5(4):364-375.

5. Kasaboğlu O, Başal Z, Usubütün A. Glandular odontogenic cyst presenting as a dentigerous cyst: A case report. J Oral Maxillofac Surg. 2006;64(4):731-733.
6. Araújo de Morais HH, José de Holanda Vasconcellos R, de Santana Santos T, Guedes Queiroz LM, Dantas da Silveira ÉJ. Glandular odontogenic cyst: Case report and review of diagnostic criteria. J Craniomaxillofac Surg. 2012;40(2):e46-e55.

7. Krishnamurthy A, Sherlin HJ, Ramalingam K, et al. Glandular odontogenic cyst: Report of two cases and review literature. Head Neck Pathol. 2009;3(2):153-158.

8. Kaplan I, Anavi Y, Hirshberg A. Glandular odontogenic cyst: A challenge in diagnosis and treatment. Oral Dis. 2008;14(7):575-581.

9. Patil AA, Barpande SR, Bhavthankar JD, Mandale MS. Glandular odontogenic cyst presenting as an aggressive multifocal lesion: Case report and review literature. Int J Oral Maxillofac Pathol. 2014;5(2):13-17.

10. Kaplan I, Anavi Y, Manor R, Sulkes J, Calderon S. The use of molecular markers as an aid in the diagnosis of glandular odontogenic cyst. Oral Oncol. 2005;41(9):895-902.

11. Pires FR, Chen SY, da Cruz Perez DE, de Almeida OP, Kowalski LP. Cytokeratin expression in central mucoepidermoid carcinoma and glandular cyst. Oral Oncol. 2004;40(5):545-551.

12. de Sousa SO, Cabezas NT, de Oliveira PT, de Araújo VC. Glandular odontogenic cyst: Report of a case with cytokeratin expression. Oral Surg Oral Med Oral Pathol Oral Radiol Endod. 1997;83(4):478-483.

13. Vered M, Allon I, Buchner A, Dayan D. Is maspin immunolocalization a tool to differentiate central low-grade mucoepidermoid carcinoma from glandular odontogenic cyst? Acta Histochem. 2010;112(2):161-168.

14. Khan HA, Loya A, Azhar R, Din NV, Bell D. Central mucoepidermoid carcinoma, a case report with molecular analysis of the TORC1/MAML2 gene fusion. Head Neck Pathol. 2010;4(3):261-264.

15. Macdonald-Jankowski DS. Glandular odontogenic cyst: Systematic review. Dentomaxillofac Radiol. 2010;39(3):127-139.

16. Boffano P, Cassarino E, Zavattero E, Campisi P, Garzino-Demo P. Surgical treatment of glandular odontogenic cysts. J Craniofac Surg. 2010;21(3):776-780.

17. Manojlović S, Grgurević J, Knezević G, Kruslin B. Glandular odontogenic cyst: A case report and clinicopathologic analysis of the relationship to central mucoepidermoid carcinoma. Head Neck. 1997;19(3):227-231.

18. Prabhu S, Rekha K, Kumar G. Glandular odontogenic cyst mimicking central mucoepidermoid carcinoma. J Oral Maxillofac Pathol. 2010;14(1):12-15.

19. Eversole LR, Sabes WR, Rovin S. Aggressive growth and neoplastic potential of odontogenic cysts: With special reference to central epidermoid and mucoepidermoid carcinomas. Cancer. 1975;35(1):270-282.

20. Keszler A, Piloni MJ. Malignant transformation in odontogenic keratocysts. Case report. Med Oral. 2002;7(5):331-335.

21. Masthan KMK, Rajkumari S, Deepasree M, Aravindha Babu N, Leena Sankari S. Neoplasms associated with odontogenic cysts. J Dent Oral Hyg. 2011;3(10):123-130.

22. Aggarwal $P$, Saxena S. Aggressive growth and neoplastic potential of dentigerous cysts with particular reference to central mucoepidermoid carcinoma. Br J Oral Maxillofac Surg. 2011;49(6):e36-e39.

23. Stoelinga PJ, Bronkhorst FB. The incidence, multiple presentation and recurrence of aggressive cysts of the jaws. J Craniomaxillofac Surg. 1988;16(4):184-195.

24. Chan KC, Pharoah M, Lee L, Weinreb I, Perez-Ordonez B. Intraosseus mucoepidermoid carcinoma: A review of the diagnostic imaging features of four jaw cases. Dentomaxillofac Radiol. 2013;42(4):20110162.

25. Mascitti M., Santarelli A, Sabatucci A. Glandular odontogenic cyst: Review of literature and report of a new case with cytokeratin-19 expression. Open Dent J. 2014;8:1-12.

26. Moghadam SA, Moghadam AF. Intraosseus mucoepidermoid carcinoma: Report of two cases. J Dent (Shiraz). 2014;15(2):86-90. 